\title{
Aberrant Expression of Fra-1 in Estrogen Receptor-negative Breast Cancers and Suppression of their Propagation In Vivo by Ascochlorin, an Antibiotic that Inhibits Cellular Activator Protein-1 Activity
}

\author{
Hiroo Nakajima, Naruhiko Mizuta, Koichi Sakaguchi, Ikuya Fujiwara, Mitsuhiko Mizuta, \\ Chiharu Furukawa, Young-Chae Chang, Junji Magae
}

Received: August 11, 2007 / Accepted: October 9, 2007

(C) Japan Antibiotics Research Association

\begin{abstract}
Estrogen receptor-negative breast cancers generally are highly malignant, resistant to chemotherapy and poorly prognostic. Here we demonstrate that estrogen receptor-negative human breast cancer cell lines highly express Fra-1, c-Fos and c-Jun, components of the transcription factor, activator protein-1 (AP-1). Retrospective observation of breast cancer tissues obtained by core needle biopsy before surgery from stages II and III patients demonstrates that Fra-1 expression is high in estrogen receptor-negative human breast cancers, and negatively correlated to paclitaxel sensitivity. Ascochlorin, which suppresses cellular AP-1 activity, selectively kills estrogen receptor-negative human and mouse breast cancer cell lines, and prolongs the survival time of mice implanted with an estrogen receptor-negative mammary carcinoma. These results suggest that chemotherapy targeting AP-1 activity is a potent strategy for estrogen receptor-negative human breast cancers.
\end{abstract}

Keywords ascochlorin, AP-1, Fra-1, breast cancer, estrogen receptor

H. Nakajima, N. Mizuta, K. Sakaguchi, I. Fujiwara: Department of Endocrine and Breast Surgery, Kyoto Prefectural University of Medicine, Kawaramachi, Hirokoji, Kamikyo-ku, Kyoto 602-0841, Japan

M. Mizuta: Department of Anesthesiology, Kyoto Prefectural University of Medicine, Kawaramachi, Hirokoji, Kamikyo-ku, Kyoto 602-0841, Japan

\section{Introduction}

Systemic treatments for breast cancer, including the combination of surgery, hormone therapy, chemotherapy and irradiation, are commonly believed to be effective in prolonging the survival of breast cancer patients. Despite the different genomic background of each breast cancer, the most important factors for prognosis are estrogen receptor (ER) expression and HER2 gene expression [1, 2]. It is now particularly clear that patients with ER-positive tumors benefit substantially from hormone therapy [3]. For patients with ER-negative tumors, on the other hand, no effective therapeutic regimens have been established, and prognosis is generally poor. It is therefore important to find new agents that are selectively effective against ER-negative breast cancer cells.

Ascochlorin is a prenylphenol antibiotic (Fig. 1), originally isolated as an anti-virus agent produced by an incomplete fungus, Ascochyta visiae [4, 5]. Ascochlorin and its derivatives exhibit a large variety of physiological activities including hypolipidemic activity [6, 7],

J. Magae (Corresponding author), C. Furukawa: Radiation Safety Research Center, Nuclear Technology Research Laboratory, Central Research Institute of Electric Power Industry, 2-11-1 Iwado Kita, Komae-shi, Tokyo 201-8511, Japan,

E-mail: jmagae@sannet.ne.jp

Y.-C. Chang: Department of Pathology, Catholic University of Daegu School of Medicine, Daegu, 3056-6, Daemyung-4-Dong, Nam-gu, Daegu, 705-718, Korea 


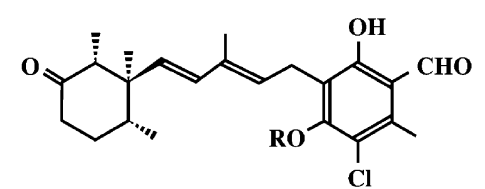

$R=\mathbf{H}:(-)$-Ascochlorin

R = Me: 4- $O$-Methylascochlorin (MAC)

$\mathrm{R}=\mathrm{CH}_{2} \mathrm{CO}_{2} \mathrm{H}: 4-O-$ Carboxymethylascochlorin (AS-6)

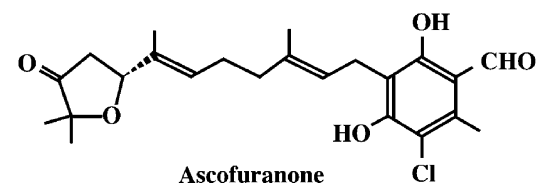

Fig. 1 Structures of ascochlorin and its derivatives.

suppression of hypertension [8], amelioration of types I and II diabetes [9, 10], immunomodulation [11, 12], and antitumor activity through the phagocyte-mediated activation of innate immunity $[12,13]$. Ascochlorin and ascofuranone, one of its derivatives, moderate oxidative phosphorylation by inhibiting ubiquinone-dependent electron transport in isolated mitochondria [14 16] and it is suggested that the antiviral activity of ascochlorin and the macrophage activation of ascofuranone are caused by this inhibitory activity on mitochondrial respiration $[14,15$, 17]. These compounds also modulate the activity of nuclear hormone receptors, and ascochlorin activates the transcription of human ER [18, 19], thus suggesting that mechanisms other than those involving the respiratory chain contribute to their physiological activities.

We recently found that ascochlorin and ascofuranone selectively suppress activator protein-1 (AP-1) activity in human cells, as well as the transcription and protein expression of its downstream targets, such as matrix metalloproteinase-9, through inhibition of the Erk signaling pathway [20,44]. Proteome analysis of human osteosarcoma cells suggests that ascochlorin causes a decrease in epidermal growth factor receptor expression, which is commonly linked to overexpression of HER2 antigen in breast cancers [49]. AP-1 is a family of homodimeric or heterodimeric transcription factors composed of basic region-leucine zipper proteins that belong to the Jun (c-Jun, JunB and JunD), Fos (c-fos, FosB, Fra-1 and Fra-2), Jun dimerization partners (JDP1 and JDP2) and closely related transcription activating factors (ATF2, LRF1/ATF3 and BATF) [21 23]. AP-1 has been implicated in transcriptional regulation of a wide range of genes participating in cell survival, proliferation, oncogenesis and apoptosis. Correlation between AP-1 and malignancy in human breast cancers has been reported. ER-negative breast cancer cell lines have high AP-1 activity mainly through high Fra-1 constitutive expression [24]. Gene expression profiling of human breast cancer cells indicates that Fra-1 and vimentin, both of which are downstream targets of AP-1 $[23,25]$, are consistently associated with a highly aggressive phenotype [26]. Through the ectopic expression Fra-1 in ER-negative cells and gene silencing of Fra-1 in ER-positive cells, it has been shown that Fra-1 expression is positively correlated with a malignant phenotype of breast cancer cells [27]. Moreover, overexpression of c-Jun in ER-positive cells increases Fra-1 expression and diminishes ER expression, resulting in increased aggressiveness [28].

In our screening of novel therapeutic agents for human breast cancers, we have found that ascochlorin selectively kills the human ER-negative breast cancer cell line MX-1 through the induction of apoptosis [29]. Expression of AP-1 components, including c-Jun, c-Fos and Fra-1, is significantly increased in $\mathrm{MX}-1$, and ascochlorin inhibits tumor promoter-induced AP-1 activity, which is dramatically elevated in MX-1 compared to the ER-positive breast cancer cell line ZR75-1. In this report, we confirm the correlation of ER-expression and expression of AP-1 components using a variety of human breast cancer cell lines and tissue sections from breast cancer patients, and found that ascochlorin demonstrated selective cytotoxicity toward these ER-negative breast cancer cell lines. We also found that intraperitoneal treatment with ascochlorin elongates the life span of mice implanted with ER-negative mammary carcinoma. Our results suggest that, by targeting AP-1, ascochlorin is an effective chemotherapeutic agent for ER-negative breast cancers.

\section{Materials and Methods}

\section{Ascochlorin}

Ascochlorin was obtained from Chugai Pharmaceutical Co. (Tokyo, Japan). It was dissolved in dimethylsulfoxide at $10 \mathrm{mg} / \mathrm{ml}$ as a stock solution and appropriately diluted with medium for addition to the culture medium, or with phosphate-buffered saline (PBS, pH 7.4, Sigma, St. Louis, MO, USA) containing $0.5 \%$ tween 80 for in vivo administration. Two hundred $\mu \mathrm{l}$ of the solution was injected $i p$ for the treatment of each mouse.

\section{Antibodies}

Antibodies for ER $\alpha$, c-Fos, Fra-1 and Bcl-2 were purchased from Santa Cruz Biotechnology (Santa Cruz, CA, USA); those for c-Jun and HER1 from Cell Signaling Technol. Inc. (Danvers, MA, U.S.A.); that for HER2 from Nichirei Co. Ltd. (Tokyo, Japan); and that for $\beta$-actin from Abcam Limited (Cambridgeshire, UK). 


\section{Cell Culture}

Human breast cancer cell lines, MDA-MB-435s, MDAMB-231, BT-549, HS578T, ZR75-1, and T-47D were purchased from American Type Culture Collection (Manassas, VA, USA). KPL-3c was kindly provided by Dr. J. Kurebayashi (Kawasaki Medical College, Okayama, Japan) [30]. MX-1 was kindly provided by Kyowa Hakko Inc. (Tokyo, Japan). A murine mammary carcinoma, FM3A, was purchased from Human Cell Science (Osaka, Japan). All cells were cultured and maintained in D-MEM supplemented with $5 \%$ fetal bovine serum.

\section{MTT Dye Reduction Assay}

Cell viability of drug-exposed breast cancer cells was determined by dimethylthiazol diphenyltetrazolium (MTT) dye reduction assay, which measures mitochondrial respiratory function [31]. Briefly, breast cancer cells $\left(5 \times 10^{4}\right.$ cells/well) were plated in 96-well flat-bottomed plates (Nunc, Roskilde, Denmark) and allowed to adhere for 24 hours. After incubation, cells were exposed to the drug for 48 hours and then incubated with MTT dye (Roche Diagnosis, $100 \mu \mathrm{g} /$ well) for 4 hours. The resultant formazan deposits were solubilized with $20 \mu \mathrm{l}$ of $10 \%$ SDS, and the absorbance at $590 \mathrm{~nm}$ was measured. All data were calculated and expressed as percent A590 of control cells (without treatment, set at 100\%).

\section{Western Blotting}

Exponentially growing cells $\left(2 \times 10^{5}\right)$ were trypsinized and suspended in $50 \mu \mathrm{l}$ of SDS sample buffer $(120 \mathrm{mM}$ Tris, $4.0 \%$ SDS, $20 \%$ glycerol, $0.1 \mathrm{mg} / \mathrm{ml}$ bromophenol blue, $100 \mathrm{mM}$ dithiothreitol, $\mathrm{pH}$ 6.8). After SDS-PAGE, Western blotting of all samples was performed as described previously [32], using first antibodies and the corresponding second antibodies for whole immunoglobulins from mouse or rabbit (Amersham Biosciences, Buckinghamshire, UK). Protein signals were visualized by fluorescence emission using a commercial kit (Roche Diagnosis, Mannheim, Germany).

\section{Histological Analysis}

Breast cancer tissues were excised by core needle biopsy from patients before each of their 12 weekly paclitaxel treatments ( $80 \mathrm{mg} / \mathrm{m}^{2}, 12$ times before surgery), fixed with $10 \mathrm{mM}$ phosphate-buffered $10 \%$ formalin, and embedded in paraffin. Samples were serially sectioned at $5.0 \mu \mathrm{m}$ and processed for hematoxylin and eosin staining and immunohistochemistry as described previously [33, 34]. We obtained informed consent from all patients to present and publish data derived from their tissue samples.

\section{Antitumor Activity}

Six-week-old Female C3H/He mice were purchased from Sankyo Lab Service Inc. (Tokyo, Japan). The mice were given a diet of commercial food pellets and water ad libitem. FM3A cells cultured in vitro were expanded in peritoneal cavity of $\mathrm{C} 3 \mathrm{H} / \mathrm{He}$ mice, and stored in liquid nitrogen. FM3A cells frozen out were ip implanted to mice, and harvested 5 days after the implantation. After washing twice with PBS, cells were suspended in PBS, and $1 \times 10^{6}$ cells/mouse were implanted ip. Antitumor activity was assessed by time of survival. The animal studies were conducted in the animal facility of Institute of Research and Innovation in accordance with the institutional guidelines for laboratory animal care under approved protocols.

\section{Statistical Analysis}

The results were statistically analyzed with a two-tailed $t$ test, judging the significance by a $p$ value less than 0.05 .

\section{Results}

Selective Cytotoxic Effect of Ascochlorin on ER-negative Human Breast Cancer Cell Lines

We previously found that ER-negative human breast cancer cell lines have higher AP-1 activity and express higher amounts of AP-1 components, including c-Jun, c-Fos, and Fra-1, compared to ER-positive cell lines. An antitumor antibiotic, ascochlorin selectively kills ER-negative breast cancer cell lines through the induction of apoptosis [29]. We further confirmed the selective cytotoxicity of ascochlorin using various human breast cancer cell lines. MX-1, MDA-MB-231, MDA-MB-435s, BT-549, and HS578T are ER-negative cell lines, while ZR75-1, KPL-3c, and T-47D are ER-positive cell lines (Fig. 2A). HER1 is expressed in all the ER-negative cell lines except MX-1 and MDA-MB-435s, while HER2 is expressed in both types of cell lines except MDA-MB-435s. Bcl-2, an anti-apoptotic factor, is expressed in ER-negative cell lines with the exception of HS578T, although KPL-3c also expresses a high amount of Bcl-2. Expression levels of Fra-1, c-Fos, and c-Jun are elevated in ER-negative cell lines without exception. Ascochlorin showed the most profound cytotoxicity on HS578T and BT-549, with moderate cytotoxicity toward MDA-MB-435s, MDA-MB-231, and MX-1, whereas T-47D, KPL-3c and ZR75-1, the three ER-positive cell lines, were resistant to ascochlorinmediated cytotoxicity (Fig. 2B). These results suggest that ascochlorin, which suppresses cellular AP-1 activity, generally exhibits selective cytotoxicity toward ER-negative 

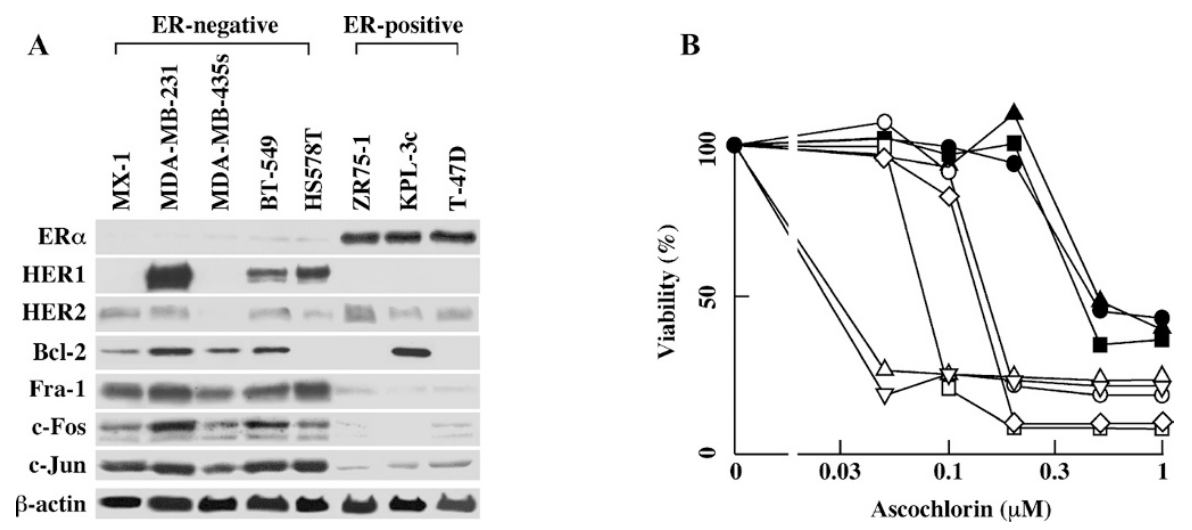

Fig. 2 Selective cytotoxic effect of ascochlorin on ER-negative human breast cancer cell lines.

(A) Protein expression of human breast cancer cell lines was analyzed by Western blot. (B) Ascochlorin was incubated for 48 hours with human breast cancer cell lines that are ER positive (T47D, filled circles; ZR75-1, filled triangles; KPL-3c, filled squares) or ER negative (MDA-MB231, open circles; BT549, open triangles; MDA435s, open squares; MX-1, open diamonds; HS578T, open inverted triangles). Cell viability was determined by MTT assay. Each value represents the mean of three independent cultures.

human breast cancer cell lines, which express higher levels of AP-1 components.

\section{Expression of Fra-1 is Negatively Correlated to ER- expression and Associated with Paclitaxel Resistance in Human Breast Cancers}

Because accumulated evidence suggests that Fra-1 expression is positively correlated with malignancy in human breast cancers [24, 26, 27], we examined Fra-1 expression in tissue sections of cancers from patients with stages II and III breast cancers, including paclitaxelsensitive cancers (Fig. 3A,B), cancers in progressive disease (PD) or no change (NC) after paclitaxel therapy (Fig. $3 \mathrm{C} \sim \mathrm{H}$ ). Although lymph node metastasis was observed in several patients, no distant metastasis was found in any of these patients. In the retrospective observation of cancer tissues obtained by core needle biopsy before surgery, Fra-1 expression was remarkably low in breast cancers sensitive to paclitaxel compared to those resistant to paclitaxel therapy. These paclitaxelsensitive cancers expressed ER and progesterone receptor (PgR). Among paclitaxel-resistant cancers, Fra-1 expression was much higher in ER-negative cancers than in ER-positive cells, while HER2 was expressed independent of Fra-1 expression level. We also stained these cancer tissues with anti-c-Fos antibody, but failed to find marked differences among the cancers (data not shown). These results suggest that Fra-1 expression is tightly linked to ER status and, consequently, to drug-resistance of human breast cancers.

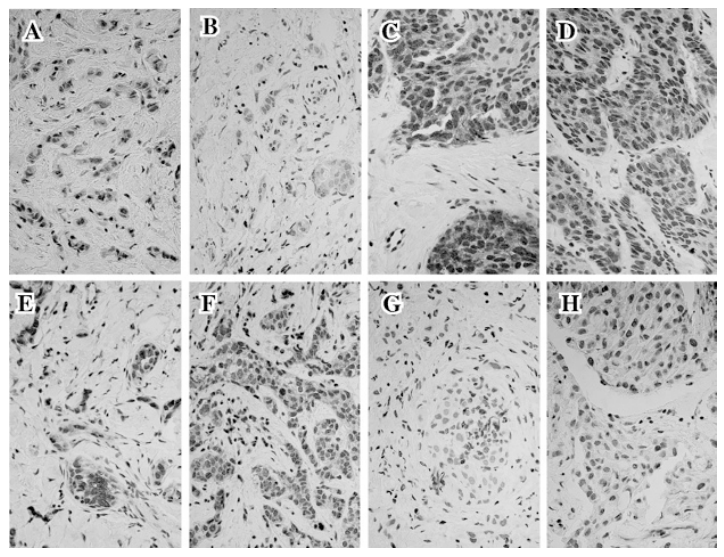

Fig. 3 Fra-1 expression of breast cancer tissues from core needle biopsy.

Cancer tissues from patients with the following breast cancer phenotypes were obtained by core-needle biopsy before each of 12 weekly paclitaxel therapy $\left(80 \mathrm{mg} / \mathrm{m}^{2}, 12\right.$ times) and subsequent surgery. Tissue sections were stained with anti-Fra-1 antibody. (A, B) Paclitaxel-responsive cancers. (A) Stage IIB (T2, NO, MO), $\mathrm{ER}^{+}, \mathrm{PgR}^{+}, \mathrm{HER} 2^{+}$. (B) Stage IIIB (T4b, N2, M0), $\mathrm{ER}^{+}, \mathrm{PgR}^{+}$, $\mathrm{HER} 2^{+}$. $(\mathrm{C} \sim \mathrm{H})$ Patients in progressive disease (PD) or no change (NC) after paclitaxel therapy. (C) Stage IIIB (T4b, N2, M0), ER ${ }^{-}$, $\mathrm{PgR}^{-}, \mathrm{HER} 2^{-}$. (D) Stage IIIB (T4c, N2, M0), ER ${ }^{-}, \mathrm{PgR}^{-}, \mathrm{HER} 2^{-}$. (E) Stage IIIB (T4C, N1, M0), ER ${ }^{-}, \mathrm{PgR}^{-}, \mathrm{HER} 2^{+}$. (F) Stage IIIA (T3, N2, $\mathrm{MO}), \mathrm{ER}^{-}, \mathrm{PgR}^{-}, \mathrm{HER}^{+}$. (G) Stage IIB (T2, NO, MO), $\mathrm{ER}^{+}, \mathrm{PgR}^{+}$, $\mathrm{HER}^{+}{ }^{+}$. (H) Stage IIIA (T3, N1, MO), ER ${ }^{+}, \mathrm{PgR}^{-}, \mathrm{HER}^{+}$.

\section{In Vivo Efficacy of Ascochlorin on an ER-negative Breast Cancer Cell Line in a Murine Experimental Model}

In vivo efficacy of ascochlorin on an ER-negative breast cancer was assessed using a murine mammary carcinoma, 
A

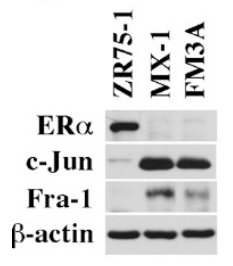

B

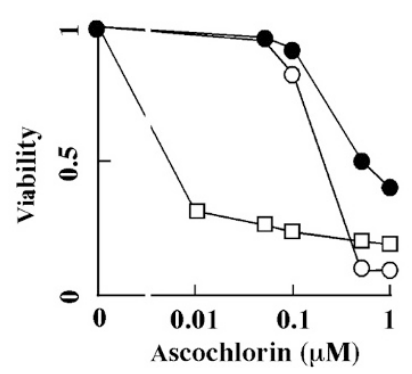

C

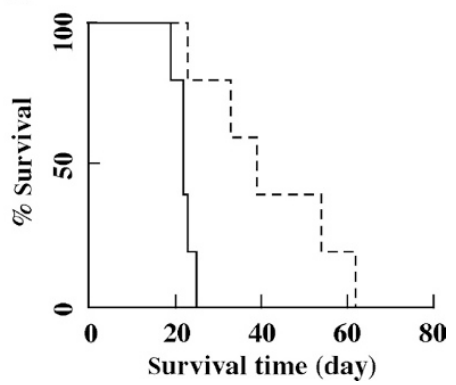

Fig. 4 Antitumor activity of ascochlorin on ER-negative mammary carcinoma in vivo.

(A) Protein expression in FM3A cells was compared with human breast cancer cell lines expressing ER (ZR75-1), or no ER (ZX-1) by Western blot. (B) FM3A cells (open squares), human breast cancer cell lines, MX-1 (open circles) and ZR75-1 (filled circles), were cultured with ascochlorin for 48 hours, and cell viability was determined by MTT assay. Each value represents the mean of three independent cultures. (C) Mice (five mice/group) were implanted with FM3A cells, and ascochlorin (2 mg/kg) was administered ip 3 times/week beginning 24 hours after implantation and continuing until death. Mean survival times (in days) of the untreated group (solid line) and ascochlorin-treated group (dashed line) are 22.20 \pm 2.17 , and $42.20 \pm 15.77$, respectively. The difference is statistically significant ( $p<0.05$, two-tailed t-test).

FM3A, implanted ip in syngeneic $\mathrm{C} 3 \mathrm{H} / \mathrm{He}$ mice. Through Western blotting, we confirmed that FM3A expressed no ER but did express abundant amounts of c-Jun and Fra-1, as in the human ER-negative breast cancer cell line MX-1 (Fig. 4A). The cytotoxic effect of ascochlorin on FM3A was observed at much lower concentrations, above $10 \mathrm{nM}$, compared to MX-1 or ZR75-1 (Fig. 4B). We treated the mice ip with ascochlorin from 24 hours after the intraperitoneal implantation of FM3A, 3 times/week until death. While all the mice in the untreated group died within 25 days, mice treated with $2.0 \mathrm{mg} / \mathrm{kg}$ ascochlorin survived for up to 60 or more days (Fig. 4C). Average survival times for the untreated and ascochlorin-treated groups are $22.20 \pm 2.17$ and $42.20 \pm 15.77$ days $(p<0.05)$, respectively. Treatment of mice with $4.0 \mathrm{mg} / \mathrm{kg}$ ascochlorin killed mice with toxicity. These results suggest that ascochlorin is a potent therapeutic agent for ER-negative breast cancers.

\section{Discussion}

It is generally observed that ER expression is negatively correlated to malignant properties in human breast cancers $[24,26,27]$, and a novel therapeutic strategy is warranted for ER-negative breast cancers to improve poor prognosis. We previously found that ascochlorin selectively kills ERnegative human breast cancer cell lines [29]. ER-negative breast cancer cell lines show increased AP-1 activity and expression of AP-1 components, and ascochlorin effectively suppresses the AP-1 activity induced by PMA. In this work we confirmed the aberrant expression of AP-1 family members in a wide variety of ER-negative human breast cancer cell lines. These cell lines were highly sensitive to ascochlorin compared to ER-positive human breast cancers. We also confirmed a high expression level of Fra-1 in ER-negative tumor tissues from breast cancer patients, and that paclitaxel-sensitive breast cancers express Fra-1 at a low level. Selective expression in ER-negative breast cancer was not observed with c-Fos. Gene expression profiling of human breast cancers suggests that only vimentin and Fra-1 are associated with an aggressive phenotype of human breast cancer [26]. Our findings are consistent with this observation.

These results prompted us to investigate the in vivo efficacy of ascochlorin on breast cancers. We used a murine experimental model in which murine FM3A cells, which are ER negative and express c-Jun and Fra-1 abundantly, were implanted into the peritoneal cavity of syngeneic mice. Intraperitoneal treatment of mice with ascochlorin significantly suppressed tumor growth and elongated survival time. Although further studies including improvement of drug delivery and therapeutic index through the chemical modification is necessary for clinical application, this result demonstrates that suppression of AP-1 is potent therapeutic strategy for ER-negative breast cancer cells that have aberrant AP-1 activity. We previously reported that an AP-1 decoy oligonucleotide which specifically binds intracellular AP-1 inhibits AP-1 transcription and cell invasion as effectively as ascochlorin [20]. We have shown that our decoy strategy effectively inhibits specific transcription factor activity and pathogenic disorders in vivo [35]. A genetic strategy targeting AP-1 activity also might be effective for treatment of ERnegative breast cancers. 
Expression of ER is negatively correlated with AP-1 activity and expression of its components, especially Fra-1, in human breast cancers [24, 26 29]. We confirmed this correlation in a wide variety of human cell lines, as well as in breast cancer tissues from patients. Although normal and immortal human mammary epithelial cells have a high basal level expression of AP-1 activity, AP-1 activity and expression of AP-1 components decrease as the breast epithelial cells progress through the stages of carcinogenic transformation [36]. However, ectopic expression of c-Jun in the ER-positive MCF-7 breast cancer cell line produces increased cellular motility and in vitro chemoinvasion, acquisition of tumor forming activity in nude mice in the absence of exogenous estrogen, and diminished ER transcription, accompanied by increased expression of Fra1 [28]. This study suggests that loss of ER expression and increased malignancy in transformed breast cancer cells are caused by activation of AP-1. AP-1 maintains cellular homeostasis [23]. AP-1 activation may compensate for growth signals from the ER required for the growth of breast cancer cells, and provide selection pressure for ERnegative cells. Conversely hormonal therapy may select hormone-unresponsive, ER-negative cells through the induction of high AP-1 activity resulting in recurring tumors with highly malignant phenotypes, which are observed in many human patients [37] and in nude mice transplanted with human breast cancers [38].

Many studies have demonstrated a crucial role for Fra-1 in the transformation of various cell types. Ectopic expression of Fra-1 in RatA fibroblasts induces tumorigenicity [25]. NIH3T3 clones, which overexpress the ras oncogene, accumulate AP-1 components including cJun, JunB, Fra-1 and Fra-2, and ectopic co-expression of cJun and Fra-1 in the fibroblasts lead to a transformed phenotype, attenuation of cFos serum inducibility, increased AP-1 activity, and cyclin $\mathrm{D}_{1}$ accumulation [39]. Silencing of Fra-1 in ER-negative breast cancer cell lines decreases growth and malignant phenotypes. Conversely, overexpression of Fra-1 in ER-positive breast cancer cell lines promotes growth on Matrigel and increases AP-1 activity and transcription of its downstream targets related to the invasive phenotype [27]. Neoplasmic transformation of rat thyroid cells is associated with a drastic increase of JunB and Fra-1, and transfection with fra-1 antisense RNA significantly reduces the malignant phenotype [40]. Epithelioid adenocarcinoma cells have enhanced activity of AP-1 due to high expression of Fra-1 and Fra-2, and exogenous expression of fra-1 in epithelioid cells endows the cells with phenotypes characteristic of late-stage tumor progression [41]. AP-1 binding to DNA is dramatically increased in asbestos-induced mesothelial cell transformation, and Fra-1 binding to DNA is specifically increased in rat mesothelioma cell lines, compared to normal rat mesothelial cells [42]. Transfection with the dominant-negative fra-l construct reverses the transformed phenotype of mesothelioma cells and anchorage-independent growth in soft agar. Upon serum stimulation of resting cells, Fra-1 is induced in the nucleus after c-Fos induction, and degradation of c-Fos is requisite for Fra-1 entry into nucleus and the resultant induction of cyclin $\mathrm{D}_{1}$ and $\mathrm{G}_{0}$-to- $\mathrm{G}_{1}$ transition [43], suggesting that Fra1 expression is essential for the growth promotion and malignant progression of human cancers. These results underscore the therapeutic potential of ascochlorin for chemotherapy-resistant malignant cancers other than breast cancers.

Among derivatives of ascochlorin, inhibitory activity of AP-1 is observed with ascochlorin and ascofuranone, but not with AS-6 and MAC, in which 4'-hydroxygroup of aromatic ring of ascochlorin is substituted by carboxylmethoxyl- and methoxyl-moiety, respectively (Fig. 1) $[20,44]$. Ascochlorin and ascofuranone inhibits mitochondrial respiration, but AS-6 and MAC dramatically decrease the inhibitory activity (unpublished result), suggesting that AP-1 inhibition and selective toxicity to ER-negative breast cancer is related to mitochondria respiration. This is supported by the observation that antimycin A also exhibits selective cytotoxic effect on ER-negative breast cancer cell lines (unpublished result). The majority of intracellular reactive oxygen species (ROS) is derived from mitochondria, and under normal metabolic condition, complex III (ubiquinone-cytochrome c reductase) is the main site of ROS production [45]. Thus, it is possible that ascochlorin, which inhibits ubiquinonedependent mitochondria electron transport [16], affect cellular ROS production. Although the too much ROS generation is toxic to the cells, appropriate amount of ROS can be the mediators to transmit growth signals, and thus involved in oncogenesis [46]. In fact, generation of ROS is implicated in the malignant transformation of mesothelioma caused by asbestos [47]. Moreover, AP-1 modulates inflammation and metabolic disease [48], which may explain why ascochlorin and its derivatives exhibit a large variety of physiological activities. Further study on ascochlorin may provide new insights into the mechanism for malignant transformation of human cancers.

\section{References}

1. Allred DC, Harvey JM, Berardo M, Clark GM. Prognostic and predictive factors in breast cancer by immunohistochemical 
analysis. Mod Pathol 11: 155-168 (1998)

2. Stearns V, Singh B, Tsangaris T, Crawford JG, Novielli A, Ellis MJ, Isaacs C, Pennanen M, Tibery C, Farhad A, Slack R, Hayes DF. A prospective randomized pilot study to evaluate predictors of response in serial core biopsies to single agent neoadjuvant doxorubicin or paclitaxel for patients with locally advanced breast cancer. Clin Cancer Res 9: 124-133 (2003)

3. Early Breast Cancer Trialists' Collaborative Group. Tamoxifen for early breast cancer: an overview of the randomized trials. Lancet 351: 1451-1467 (1998)

4. Tamura G, Suzuki S, Takatsuki A, Ando K, Arima K. Ascochlorin, a new antibiotic, found by the paper-disc agardiffusion method. I. Isolation, biological and chemical properties of ascochlorin (Studies on antiviral and antitumor antibiotics. I). J Antibiot 21: 539-544 (1968)

5. Nawata Y, Ando K, Tamura G, Arima K, Iitake Y. The molecular structure of ascochlorin. J Antibiot 22: 511-512 (1969)

6. Hosokawa T, Sawada M, Ando K, Tamura G. Enhanced Excretion of fecal neutralsterols and the hypercholesterolemic properties of 4-O-methylascochlorin. Agric Biol Chem 44: 2461-2468 (1980)

7. Hosokawa T, Sawada M, Ando K, Tamura G. Alteration of cholesterol metabolism by 4-O-methylascochlorin in rats. Lipids 16: 433-438 (1981)

8. Hosokawa T, Okutomi T, Sawada M, Ando K, Tamura G. Unusual concentration of urine and prevention of polydipsia by fungal prenylphenols in DOCA hypertensive rats. Eur J Pharmacol 69: 429-438 (1981)

9. Hosokawa T, Ando K, Tamura G. An ascochlorin derivative, AS-6 potentiates insulin action in streptozotocin diabetic mice and rats. Agric Biol Chem 46: 775-781 (1982)

10. Hosokawa T, Ando K, Tamura G. An ascochlorin derivative, AS-6, reduces insulin resistance in the genetically obese diabetic mice. Diabetes 34: 267-274 (1982)

11. Magae J, Suzuki S, Nagai K, Yamasaki M, Ando K, Tamura G. In vitro effects of an antitumor antibiotic, ascofuranone, on the murine immune system. Cancer Res 46: 1073-1078 (1986)

12. Magae J, Hayasaki J, Matsuda Y, Hotta M, Hosokawa T, Suzuki S, Nagai K, Ando K, Tamura G. Antitumor and antimetastatic activity of an antibiotic, ascofuranone and activation of phagocytes. J Antibiot 40: 959-965 (1988)

13. Magae J, Hosokawa T, Ando K, Nagai K, Tamura. Antitumor protective property of an isoprenoid antibiotic, ascofuranone. J Antibiot 35: 1547-1552 (1982)

14. Takatsuki A, Tamura G, Arima K. Antiviral and antitumor antibiotics. XIV. Effects of ascochlorin and other respiration inhibitors on multiplication of Newcastle disease virus in cultured cells. Appl Microbiol 17: 825-829 (1969)

15. Magae J, Munemura K, Ichikawa C, Osada K, Hanada T, Tsuji RF, Yamashita M, Hino A, Horiuchi T, Uramoto M, Yamasaki M, Endo T, Nagai K. Effects of microbial products on glucose consumption and morphology of macrophages. Biosci Biotechnol Biosci 57: 1628-1631 (1993)

16. Minagawa N, Meguro K, Sakajo S, Yoshimoto A. Effects of ascofuranone on the mitochondria isolated from Hansenula anomala. Biosci Biotechnol Biosci 58: 1334-1335 (1994)

17. Ashikaga T, Honma M, Munemura K, Kataoka T, Endo T, Yamasaki M, Magae J, Nagai K. Selective induction of interleukin-1 production and tumor killing activity of macrophages through apoptosis by the inhibition of oxidative respiration. Biosci Biotchnol Biochem 62: 1115-1121 (1998)

18. Togashi M, Masuda H, Kawada T, Tanaka M, Saida K, Ando K, Tamura G, Magae J. PPAR $\gamma$ activation and adipocyte differentiation induced by AS-6, a prenyl-phenol antidiabetic antibiotic. J. Antibiot 55: 417-422 (2002)

19. Togashi M, Ozawa S, Abe S, Nishimura T, Tsuruga M, Ando K, Tamura G, Kuwahara S, Ubukata M, Magae J. Ascochlorin derivatives as ligands for nuclear hormone receptors. J Med Chem 46: 4113-4123 (2003)

20. Hong SH, Park KK, Magae J, Ando K, Lee TS, Kwon TK, Kwak JY, Kim CH, Chang YC. Ascochlorin inhibits matrixmetalloproteinase-9 expression by suppressing AP-1 mediated-gene expression through the ERK1/2 signaling pathway: Inhibitory effects of ascochlorin on the invasion of renal carcinoma cells. J Biol Chem 280: 25202-25209 (2005)

21. Angel P, Karin M. The role of Jun, Fos and the AP-1 complex in cell-proliferation and transformation. Biochim Biophys Acta 1072: 129-157 (1991)

22. Vogt PK. Jun, the oncoprotein. Oncogene 20: 2365-2377 (2001)

23. Shaulian E, Karin M. AP-1 in cell proliferation and survival. Oncogene 20: 2390-2400 (2001)

24. Philips A, Teyssier C, Galtier F, Rivier-Covas C, Rey JM, Rochefort H, Chalbos D. FRA-1 expression level modulates regulation of activator protein-1 activity by estradiol in breast cancer cells. Mol Endocrinol 12: 973-985 (1998)

25. Bergers G, Graninger P, Braselmann S, Wrighton C, Busslinger M. Transcriptional activation of the fra-1 gene by AP-1 is mediated by regulatory sequences in the first intron. Mol Cell Biol 15: 3748-3758 (1995)

26. Zajchowski DA, Bartholdi MF, Gong Y, Webster L, Liu HL, Munishkin A, Beauheim C, Harvey S, Ethier SP, Johnson $\mathrm{PH}$. Identification of gene expression profiles that predict the aggressive behavior of breast cancer cells. Cancer Res 61: 5168-5178 (2001)

27. Belguise K, Kersual N, Galtier F, Chalbos D. FRA-1 expression level regulates proliferation and invasiveness of breast cancer cells. Oncogene 24: 1434-1444 (2005)

28. Smith LM, Wise SC, Hendricks DT, Sabichi AL, Bos T, Reddy P, Brown PH, Birrer MJ. cJun overexpression in MCF-7 breast cancer cells produces a tumorigenic, invasive and hormone resistant phenotype. Oncogene 18: 6063-6070 (1999)

29. Sakaguchi K, Nakajima H, Mizuta N, Furukawa C, Ozawa 
S, Ando K, Chang YC, Yamagishi H, Magae J. Selective cytotoxicity of ascochlorin in ER-negative human breast cancer cell lines. Biochem Biophys Res Commun 329: 46-50 (2005)

30. Kurebayashi J, Kurosumi M, Sonoo H. A new human breast cancer cell line, KPL-3C secretes parathyroid hormonerelated protein and produces tumours associated with microcalcifications in nude mice. Br J Cancer 74: 200-207 (1996)

31. Mosmann T. Rapid colorimetric assay for cellular growth and survival: application to proliferation and cytotoxicity assays. J Immunol Methods 65: 55-63 (1983)

32. Lee YS, Nakajima H, Tsuruga M, Magae J. Elimination of cell cycle regulators during caspase-3-dependent apoptosis by an immunosuppressant, FTY720. Biosci Biotechnol Biochem 6: 467-474 (2003)

33. Hakuno N, Koji T, Yano T, Kobayashi N, Tsutsumi O, Taketani Y, Nakane PK. Fas/APO-1/CD95 system as a mediator of granulosa cell apoptosis in ovarian follicle atresia. Endocrinology 137: 1938-1948 (1996)

34. Koji T, Hishikawa Y, Ando H, Nakanishi Y, Kobayashi N. Expression of Fas and Fas ligand in normal and ischemiareperfusion testes: Involvement of the Fas system in the induction of germ cell apoptosis in the damaged mouse testis. Biol Reprod 64: 946-954 (2001)

35. Ahn JD, Morishita R, Kaneda Y, Kim HJ, Kim YD, Lee HJ, Lee KU, Park JY, Kim YH, Park KK, Chang YC, Yoon KH, Kwon HS, Park KG, Lee IK. Transcription factor decoy for AP-1 reduces mesangial cell proliferation and extracellular matrix production in vitro and in vivo. Gene Ther 11: 916-923 (2004)

36. Smith LM, Birrer MJ, Stampfer MR, Brown PH. Breast cancer cells have lower activating protein 1 transcription factor activity than normal mammary epithelial cells. Cancer Res 57: 3046-3054 (1997)

37. Johnston SR, Lu B, Scott GK, Kushner PJ, Smith IE, Dowsett M, Benz CC. Increased activator protein-1 DNA binding and c-Jun NH2-terminal kinase activity in human breast tumors with acquired tamoxifen resistance. Clin Cancer Res 5: 251-256 (1999)

38. Dumont JA, Bitonti AJ, Wallace CD, Baumann RJ, Cashman EA, Cross-Doersen DE. Progression of MCF-7 breast cancer cells to antiestrogen-resistant phenotype is accompanied by elevated levels of AP-1 DNA-binding activity. Cell Growth
Differ 7: 351-359 (1996)

39. Mechta F, Lallemand D. Pfarr CM, Yaniv M. Transformation by ras modifies AP1 composition and activity. Oncogene 14: 837-847 (1997)

40. Vallone D, Battista S, Pierantoni GM, Fedele M, Casalino L, Santoro M, Viglietto G, Fusco A, Verde P. Neoplastic transformation of rat thyroid cells requires the junB and fra1 gene induction which is dependent on the HMGI-C gene product. EMBO J 16: 5310-5321 (1997)

41. Kustikova O, Kramerov D, Grigorian M, Berezin V, Bock E, Lukanidin E, Tulchinsky E. Fra-1 induces morphological transformation and increases in vitro invasiveness and motility of epithelioid adenocarcinoma cells. Mol Cell Biol 18: 7095-7105 (1998)

42. Ramos-Nino ME, Timblin CR, Mossman BT. Mesothelial cell transformation requires increased AP-1 binding activity and ERK-dependent Fra-1 expression. Cancer Res 62: 6065-6069 (2002)

43. Burch PM, Yuan Z, Loonen A, Heintz NH. An extracellular signal-regulated kinase 1- and 2-dependent program of chromatin trafficking of c-Fos and Fra-1 is required for cyclin D1 expression during cell cycle reentry. Mol Cell Biol 24: 4696-4709 (2004)

44. Cho HJ, Kanag JH, Kwak JY, Lee TS, Lee IS, Park NG, Nakajima H, Magae J, Chang YC. Ascofuranone suppresses PMA-mediated matrix metalloproteinase-9 gene activation through the Ras/Raf/MEK/ERK and Ap 1-dependent mechanisms. Carcinogenesis 28: 1104-1110 (2006)

45. Turrens JF. Superoxide production by the mitochondrial respiratory chain. Biosci Rep 17: 3-8 (1997)

46. Forman HJ, Fukuto JM, Torres M. Redox signaling: thiol chemistry defines which reactive oxygen and nitrogen species can act as second messengers. Am J Physiol Cell Physiol 287: C246-C256 (2004)

47. Kinnula VL. Oxidant and antioxidant mechanisms of lung disease caused by asbestos fibres. Eur Respir J 14: 706-716 (1999)

48. Hotamisligil GS. Role of endoplasmic reticulum stress and c-Jun $\mathrm{NH}^{2}$-terminal kinase pathways in inflammation and origin of obesity and diabetes. Diabetes 54: S73-S78 (2005)

49. Kang JH, Park KK, Lee IS, Magae J, Ando K, Kim CH, Chang YC. Proteome analysis of responses to ascochlorin in a human osteosarcoma cell line by 2-D gel electrophoresis and MALDI-TOF MS. J Proteome Res 5: 2620-2631 (2006) 